\title{
Médiévales
}

Langues, Textes, Histoire

44 | printemps 2003

Le diable en procès

\section{Satan hérétique : l'institution judiciaire de la démonologie sous Jean XXII}

Satan the Heretic : the Judicial Institution of Demonology under John

\section{Alain Boureau}

\section{OpenEdition}

Journals

Édition électronique

URL : https://journals.openedition.org/medievales/711

DOI : 10.4000/medievales.711

ISSN : 1777-5892

\section{Éditeur}

Presses universitaires de Vincennes

\section{Édition imprimée}

Date de publication : 1 juin 2003

Pagination : 17-46

ISBN : 2-84292-142-9

ISSN : 0751-2708

\section{Référence électronique}

Alain Boureau, «Satan hérétique : l'institution judiciaire de la démonologie sous Jean xxII 》, Médiévales [En ligne], 44 | printemps 2003, mis en ligne le 02 décembre 2005, consulté le 22 avril 2022. URL http://journals.openedition.org/medievales/711 ; DOI : https://doi.org/10.4000/medievales.711

Ce document a été généré automatiquement le 22 avril 2022.

Tous droits réservés 


\title{
Satan hérétique : l'institution judiciaire de la démonologie sous Jean XXII
}

\author{
Satan the Heretic : the Judicial Institution of Demonology under John
}

\author{
Alain Boureau
}

1 Le démon a une histoire fort ancienne dans le christianisme, mais l'institution d'une science du démon, d'une démonologie paraît bien plus récente. Certes, on peut reconstituer un certain savoir patristique et scolastique sur les entreprises du diable et de ses mauvais anges, mais on ne peut parler de démonologie que lorsqu'une discipline autonome s'attache non plus seulement au mode d'existence et d'action des démons, mais aussi et surtout aux relations qu'ils nouent avec les humains et aux techniques de discernement des esprits qui permettent de distinguer le possédé de l'inspiré. Un savoir pratique, un art, fondé sur une doctrine plus ou moins précise, remplace, ou du moins complète l'antique don de reconnaissance des mauvais esprits. Un des signes concrets de cette émergence d'une nouvelle discipline se trouve dans la rédaction de traités spécifiques, qui transmettent un savoir ou une expérience cumulative. C'est pourquoi on a longtemps daté la naissance de la démonologie du premier traité connu de démonologie pratique et théorique, le Marteau des sorcières, publié en 1486 par l'inquisiteur dominicain Henri Institoris. Certes, d'autres manuels de l'inquisiteur avaient précédé, dont les plus célèbres étaient ceux de Bernard Gui ${ }^{1}$ (vers 1324) et Nicolas Eymerich (vers 1376), mais la poursuite des démons et de leurs alliés les sorciers n'y jouait pas un rôle central. La poursuite des hérétiques proprement dits et les questions techniques de procédure importaient davantage. Cette chronologie avait l'avantage de faire coïncider les débuts de la démonologie et ceux de la « démonomanie ", illustrée par la grande chasse aux sorcières.

2 Des travaux récents, notamment ceux du groupe animé par Agostino Paravicini Bagliani, et ceux de Pierrette Paravy², ont pourtant montré qu'un moment fondamental pour la constitution d'une démonologie pratique et théorique précoce devait être situé vers la fin des années 1430, avec les premiers procès minutieux en sorcellerie dans le 
Valais et avec des écrits de doctrine de procédure comme le rapport du chancelier Hans Fründ sur les sorcières du Valais, le Formicarius du dominicain Jean Nieder, le traité anonyme intitulé Errores Gazariorum ou encore le traité du juge dauphinois Claude Tholosan. Le concile de Bâle (1431-1437) aurait joué un rôle essentiel pour la confrontation des expériences et des doctrines ${ }^{3}$.

Je propose ici de faire un nouveau saut en arrière, en avançant de plus d'un siècle l'invention de la démonologie et en pointant non pas la mise en place simultanée d'une doctrine et d'une poursuite, comme au $\mathrm{Xv}^{\mathrm{e}}$ siècle, mais la mutation considérable de procédure qui a assimilé les invocations du démon et la sorcellerie au crime d'hérésie, ce qui entraîna un nouveau déploiement judiciaire, de nouvelles révélations et surtout, en donnant à l'ancien thème du pacte avec le diable un contenu doctrinal, rendait compte de l'action démoniaque dans le monde. Cette proposition peut paraître futilement nominale, car elle baptiserait du nom de démonologie de simples évolutions de mentalités ou de doctrine. Tout phénomène historique a sa préhistoire que l'on peut construire en histoire en gommant les différences et en accentuant les ressemblances. Cependant les enjeux de ce déplacement chronologique sont importants, ne serait-ce que dans la saisie historiographique des phénomènes de sorcellerie. En repoussant la démonologie vers l'extrême fin du Moyen Âge, les médiévistes se sont défaussés d'une lourde affaire qui mettait en cause la rationalité scolastique et ont ainsi perdu l'occasion de repérer les racines théologiques et philosophiques de la démonologie. La chasse aux sorcières a longtemps relevé de l'histoire "moderne"; dès lors, l'écart patent entre les lumières de la Renaissance et l'obscurité persécutrice a encore accentué la marginalisation de la pensée démonologique, réduite à un puissant combat d'arrière-garde des forces obscures et répressives qui refusaient la modernité. Depuis une vingtaine d'années, au contraire, des historiens (Jacques Chiffoleau, Nicole Lemaître, Denis Crouzet) se sont efforcés de rétablir des continuités entre le christianisme médiéval et les formes diverses de Réforme et de Contre-Réforme.

4 La présente proposition n'est pas totalement inédite: Richard Kieckhefer a écrit un stimulant petit livre sur les procès de sorcellerie qui s'ouvre précisément sur l'année $1300^{4}$. Par ailleurs, une bulle à la fois célèbre et méconnue de Jean XxII, Super illius Specula (1326 ou 1327) a parfois été considérée comme le texte fondateur de la nouvelle obsession démonologique qui saisit beaucoup d'esprits dans l'Église à la fin du Moyen Âge. Joseph Hansen, qui, au début de ce siècle, fonda les études contemporaines sur la sorcellerie, avait placé ce texte parmi les tout premiers de sa fameuse anthologie, Quellen und Untersuchungen zur Geschichte des Hexenwahns und der Hexenverfolgung ${ }^{5}$. Lynn Thorndike, trente ans plus tard, consacra un chapitre de sa somme sur la magie à Jean XXII ${ }^{6}$. Tout récemment, les travaux de Nicolas Weill-Parot ${ }^{7}$ ont rouvert la question de l'intérêt du pape pour la magie.

L'arbre des historiens et la forêt des documents

5 De fait, même si ce sont essentiellement des pratiques magiques (fabrication d'images et d'ustensiles divers) qui sont incriminées, elles dérivent directement de l'adoration des démons. Les sorciers «entrent en association avec la mort et font pacte avec l'enfer $"^{8}$, selon les termes de Super illius Specula. L'invocation des démons et les pratiques connexes sont référées à des «dogmes»: "que nul d'entre eux n'ose enseigner ou apprendre quoi que ce soit de ces dogmes pervers » (de perversis dictis dogmatibus perversis); désignées comme hérésies, elles doivent être punies «par toutes les peines que, de droit, méritent les hérétiques» (penas omnes et singulas. quas de iure 


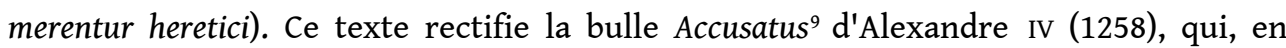
réponse à une demande, précisait que les délits magiques ne relevaient pas des compétences de l'Inquisition, sauf si elles «sentaient manifestement l'hérésie » (nisi manifeste saperent heresim). L'importance de cette qualification est évidente pour la construction ultérieure de la démonologie et du sabbat, largement opérée par le travail inquisitorial. L'inquisition, en prenant en charge l'hérésie des sorciers, pouvait y consacrer ses moyens judiciaires exceptionnels, son expertise théologique et son savoir cumulatif, transmis par de nombreux guides de l'inquisiteur, tandis que les tribunaux épiscopaux et séculiers étaient tributaires des circonstances et des compétences et engagements individuels.

6 En outre, Super illius Specula, en prenant au sérieux les prétentions des sorciers et invocateurs de démons, rompait de façon brutale avec l'ancienne tradition de l'Église et notamment du canon Episcopi ( $\mathrm{x}^{\mathrm{e}}$ siècle), qui traitait les sortilèges et les faits de sorcellerie ou de magie comme autant d'illusions diaboliques, sans réalité effective. Ce texte, que l'on trouve pour la première fois dans une collection canonique ou pénitentielle rédigée par Réginon de Prüm (vers 904), puis repris régulièrement dans d'autres séries avant de figurer au Décret de Gratien ${ }^{10}$ a toujours fasciné les historiens notamment parce qu'il annonçait, cinq siècles à l'avance, certaines formes du sabbat des sorcières: l'auteur du canon évacue ces croyances comme de simples rêveries induites par le diable qui fait croire à des esprits faibles qu'ils pouvaient tirer quelque force surnaturelle de leurs mauvaises accointances. Aucun des faits allégués n'a de réalité corporelle et ces images de chevauchée nocturne sont comparées aux songes et rêves nocturnes ordinaires. Bien plus, le canon limite sévèrement les pouvoirs du diable :

Quiconque croit qu'en dehors du Créateur lui-même, qui a tout accompli et par qui tout a été fait, une créature puisse être faite, ou changée en mieux ou en pire, ou transformée en une autre espèce ou une autre apparence est un infidèle et est pire qu'un païen.

$7 \quad$ Malgré cet écart, les historiens ont eu tendance à faire peu de cas de la bulle Super illius Specula. On a parfois douté de la portée de ce texte, en mettant en question sa nouveauté, ses effets et son authenticité.

La nouveauté du texte a pu paraître limitée, d'une part parce que l'imputation hérétique semble déjà figurer dans le canon Episcopi, d'autre part parce que la réalité des maléfices n'est pas explicitement affirmée dans la bulle de Jean $s$ infidèles et l'auteur du canon invoquait, à leur propos, un verset de l'Épître à Tite $(3,10):$ «Évite l'homme hérétique après la première et seconde correction ». Cependant, cette infidélité ou hérésie est imputée à la «fausse opinion », à la croyance en des divinités plus ou moins sataniques, et non pas à l'acte même d'invocation ou de magie. Dans la construction procédurale de Jean XXII, c'est la notion de "fait hérétique », au-delà ou en deçà de l'opinion ou de l'erreur qui importe. On y reviendra. Ensuite, la notion d'hérésie n'a pas du tout le même sens au $\mathrm{x}^{\mathrm{e}}$ siècle et au XIV ${ }^{\mathrm{e}}$ siècle; entre-temps, les grandes dissidences des $\mathrm{XI}^{\mathrm{e}}$ et $\mathrm{XII}^{\mathrm{e}}$ siècles, le valdéisme, le catharisme, le béguinisme ont conduit à la constitution de l'hérésie comme crime majeur, rapporté au crime de lèsemajesté depuis Innocent III et sa bulle Vergentis ${ }^{11}$, poursuivi selon des procédures d'exception et puni de façon rigoureuse. Il est vrai qu'une lecture minutieuse de la bulle de Jean XXII ne permet pas d'attribuer une réalité effective aux opérations de magie et d'invocation. Mais, on le verra, la longue suite des textes normatifs et des 
procès du pontificat de Jean XxII lève tout doute quant aux croyances du pape et de son entourage.

9 La seconde objection, quant aux effets de la bulle, porte surtout sur le long laps de temps entre sa publication et sa première reprise textuelle, cinquante ans plus tard, dans le Directorium Inquisitorum ${ }^{12}$ de l'inquisiteur dominicain Nicolas Eymerich (1376), qui, par ailleurs, réitérait la thèse de l'invocation des démons comme activité hérétique. Mais cette reprise ne relève pas de la seule fantaisie répressive de l'inquisiteur catalan, célèbre pour ses excès. En effet, deux ans plus tôt, le 15 août 1374, le pape Grégoire XI, qui nomma Eymerich comme inquisiteur, avait adressé à l'inquisiteur de France, le dominicain Jacques de Morey, une lettre débutant précisément par la mention Super specula militantis, qui lui recommandait de procéder de façon sommaire ${ }^{13}$ et sans appel contre les invocateurs des démons (demones invocant), et notamment quand ils étaient ecclésiastiques. Le texte du pape fait d'ailleurs saisir l'une des raisons du retard dans l'application des directives de Jean xxII ; il mentionne en effet l'opposition de certains : « quelques-uns, et même des lettrés, s'y opposent, en prétendant que cela ne relève pas de ta charge selon les décisions canoniques ${ }^{14}$. » De fait, le principal traité sur les hérésies, rédigé vers 1340, par Guido Terreni, qui avait été inquisiteur de Majorque et proche collaborateur de Jean XxII, ne mentionne nullement les adorateurs des démons parmi les hérétiques ${ }^{15}$. Bien avant les premières descriptions cohérentes et concordantes du sabbat des sorcières, à partir de 1430, la voie était ouverte au traitement inquisitorial des invocateurs de démons et, en 1398, la faculté de théologie de Paris détermina que la sorcellerie accomplie par le moyen d'un pacte explicite ou implicite avec le diable impliquait une apostasie de la foi chrétienne et donc relevait de l'hérésie ${ }^{16}$. Il nous faudra revenir sur la question du retard dans l'application effective de la bulle et même dans les perceptions communes des démons ${ }^{17}$.

10 La troisième objection, quant à l'authenticité du texte, ne peut être contournée. Certes c'est à tort qu'on a évoqué son absence dans les deux collections canoniques, qui ont achevé la composition du Corpus Iuris Canonici, en y incluant de nombreuses décrétales de Jean XXII, les Extravagantes Johannis XXII et les Extravagantes communes : en effet la première collection de vingt bulles du pape fut composée en 1325 par Jesselin de Cassagnes qui n'eut jamais le temps d'y revenir avant sa mort. La seconde ne fut assemblée que fort tardivement, au début $\mathrm{du} \mathrm{XVI}^{\mathrm{e}}$ siècle $^{18}$, en un temps où le message de Jean XXII sur ce point était devenu fort banal. Mais il est plus surprenant de ne pas trouver de trace de la bulle dans les Registres pontificaux ${ }^{19}$; cependant l'inachèvement du grand chantier de publication des lettres de Jean xxII, entrepris il y a plus d'un siècle, ne permet pas de transformer cet étonnement en doute. Enfin, le statut même de ce texte est étrange, puisqu'il s'adresse à tous les chrétiens sans distinction, en incitant les coupables à livrer leurs livres de magie sous huit jours. Or Jean XxII préféra souvent les commissions discrètes et précises, confiées à des hommes de confiance.

11 Le doute peut donc demeurer, mais la bulle Super illius specula, cet arbre malingre, et peut-être inexistant, a masqué une forêt bien réelle et empêché de repérer la grande nouveauté de la démonologie de Jean xxII. C'est dans cette forêt que nous allons circuler, en nous limitant d'abord aux aspects procéduraux, qui qualifient la magie démoniaque comme crime hérétique et qui montrent bien la continuité et l'importance de l'enquête sur les adorateurs des démons.

Un effort continu 
12 En premier lieu, on trouve une demande d'expertise formulée par Jean XXII au début de 1320 sur la qualification des pratiques magiques et des invocations des démons comme hérésie. Le texte des questions du pape et dix réponses ont été conservées dans le manuscrit Borghese 428 de la Bibliothèque Vaticane redécouvert par Annelise Maier ${ }^{20}$, dont je prépare l'édition complète. Certes, les trois premières questions, sur lesquelles nous reviendrons, traitent de sortilèges divers qui ne relèvent pas explicitement de la démonologie, mais la quatrième question est claire :

Est-ce que ceux qui sacrifient aux démons en ayant l'intention de leur faire sacrifice, afin qu'attirés par ce sacrifice, les démons obligent quelque personne à faire ce que le sacrificateur désirait, ou est-ce que ceux qui invoquent le démon doivent être considérés comme des hérétiques ou bien seulement comme des auteurs de sortilèges ${ }^{21}$ ?

13 Cette consultation, malgré la réticence de la majorité des théologiens consultés, produisit des résultats remarquables, en accréditant la thèse neuve du «fait hérétique »; l'un des experts, Enrico del Carretto, esquissa même la description d'un sacrement satanique efficace, description dérivée de la théorie contractuelle du sacrement mise au point dans la seconde moitié du XIII ${ }^{\mathrm{e}}$ siècle ${ }^{22}$.

14 Il est possible que la pratique de certains juges ecclésiastiques ait précédé l'explicitation doctrinale de la question ${ }^{23}$. C'est ce qui pourrait apparaître dans une lettre adressée, le 28 juillet 1319, par Jean XXII au chanoine Séguin de Belégney, juge ecclésiastique de Fontius d'Auch, évêque de Poitiers. Séguin s'était ouvert au pape d'un scrupule qui l'avait assailli : une accusée était morte après avoir subi la torture sur ordre du juge. L'accusée avait eu la plante des pieds brûlée aux charbons ardents ${ }^{24}$. Le chanoine se demandait donc s'il n'encourait pas l'«irrégularité », c'est-à-dire l'incapacité à demeurer dans l'ordre sacerdotal, en ce cas pour avoir versé le sang. Le pape rassura Séguin en soulignant que la victime était morte quelque temps après la torture et que «l'on pouvait douter qu'en raison des tourments, elle soit morte plus rapidement que si elle était morte sans avoir été torturée $»^{25}$.

15 La victime du juge avait été dénoncée (diffamata) publiquement pour crimes de sortilèges et perversion hérétique (super criminibus sortilegii et heretice pravitatis). On peut penser, sans certitude toutefois, que c'est le juge qui avait associé le sortilège, nommé en premier, à l'hérésie. Le recours à la torture semble avoir été dicté par le désir de découvrir des réseaux de complicité, résultat effectivement acquis et loué par le pape : «tout ce qui a été ainsi trouvé, selon toute vraisemblance, n'aurait pas été révélé si cette femme ne l'avait révélé par le biais des tourments ${ }^{26}$. On note ici une raison pratique de l'assimilation du sortilège à l'hérésie : l'usage de la torture dans un tribunal ecclésiastique avait été introduit en 1252 (Ad abolendam) par le pape Innocent IV, au seul bénéfice des inquisiteurs, et non des juges épiscopaux. Ce n'est qu'en 1308, au moment où il créait des commissions épiscopales pour juger les Templiers que Clément $\mathrm{V}$ avait étendu l'usage de la torture aux officialités, mais il s'agissait toujours exclusivement d'imputations d'hérésie. Séguin ne devait pas en être fort sûr, car il prétend ne s'être résolu à l'usage de la torture qu'après avoir pris conseil auprès de "personnes très honnêtes, qui assuraient qu'ils avaient vu dans la région toulousaine les hérétiques être examinés par les peines ${ }^{27}$.

16 Une autre affaire, connue par une lettre de juillet 1319 adressée par le pape à Jacques Fournier, évêque de Pamiers, assimile l'invocation des démons à l'hérésie. Le pontife demandait à l'évêque de poursuivre trois personnages, un clerc, un carme et une 
femme, qu'il accusait de "fabrication d'images, d'incantations et consultations de démons, d'envoûtements (fascinationibus), de maléfices ${ }^{28}$. Or Jean XXII parle plus loin de leurs « erreurs » et, dans son paragraphe d'exhortation, émet le souhait que « la foi catholique troublée par les erreurs susdites retrouve sa clarté».

Quelques semaines avant la consultation des experts, le 22 août 1320, une lettre fut envoyée, au nom du pape Jean xxII, par le cardinal Guillaume de Peyre Godin aux inquisiteurs de Carcassonne et de Toulouse, Jean de Beaune et Bernard Gui. Cette fois, et encore plus nettement que dans la bulle Super illius specula, la demande d'action judiciaire se concentre sur les invocations aux démons et sur les pactes alors conclus :

Frère Guillaume, évêque de Sabine par l'effet de la miséricorde divine envoie ses salutations à l'homme de religion...inquisiteur du crime hérétique dans la région de Carcassonne. Notre très saint père et maître, le seigneur Jean XXII, pape par l'effet de la providence divine, souhaite avec ferveur chasser du centre de la maison de Dieu les auteurs de maléfices qui tuent le troupeau du Seigneur; il ordonne et vous confie la tâche de faire enquête et de procéder, tout en conservant pourtant les modes de procédure qui vous ont été fixés, à vous et aux prélats, en matière d'hérésie par les canons, à l'encontre de ceux qui immolent aux démons ou les adorent ou leur font hommage. "Il faut aussi procéder » contre ceux qui font des pactes explicites d'obligation avec ces démons, ou qui fabriquent ou font fabriquer une image quelconque ou quoi que ce soit d'autre pour se lier au démon ou pour perpétrer quelque maléfice par l'invocation des démons, contre ceux qui, en abusant du sacrement de baptême, baptisent ou font baptiser une image de cire ou d'autre matière, ou qui, par d'autres moyens et avec invocation des démons, fabriquent ou font fabriquer ces images de quelque façon, contre ceux qui, en connaissance de cause, réitèrent le baptême, l'ordre ou la confirmation, contre ceux qui utilisent le sacrement d'eucharistie ou l'hostie consacrée et d'autres sacrements de l'Église ou quelque partie de ces sacrements quant à la forme ou à la matière, pour en abuser pour leurs sortilèges ou maléfices. Et en effet, notre maître mentionné plus haut, de science certaine ${ }^{29}$, élargit et étend à tous les cas cités, sans exception, le pouvoir donné de droit aux inquisiteurs quant à l'exercice de leur fonction contre les hérétiques, ainsi que leurs privilèges, et ce jusqu'à ce qu'il juge devoir révoquer cette extension. Nous vous signifions tout cela par nos présentes lettres patentes par le mandat spécial que nous a confié le seigneur pape, par l'oracle même de sa voix vive. Fait à Avignon, le 22 août 1320, en cette quatrième année du règne du seigneur pape ${ }^{30}$.

On peut se demander pourquoi Jean XXII ne signa pas lui-même cette lettre: il est possible que, devant la réticence des experts de la commission de 1320, le pape ait préféré une voie plus latérale pour faire connaître ses souhaits. Pourquoi Guillaume de Peyre Godin fut-il choisi comme porte-parole du pape auprès des inquisiteurs? Guillaume, né à Bayonne vers 1260, était entré fort tôt, vers 1279, chez les dominicains de Béziers, avant de circuler comme étudiant dans divers couvents et studia du SudOuest (Orthez, Bordeaux, Condom), de faire ses études de théologie à Montpellier, puis de parcourir à nouveau les couvents (Bayonne, Condom, Montpellier) comme lecteur. Il ne passa que brièvement à Paris, en 1292. Sa véritable carrière universitaire, après une période d'enseignement à Toulouse (1296), commença en 1306 quand il fut nommé lecteur du Sacré Palais auprès de Clément $\mathrm{V}$, qui le fit cardinal-prêtre de Sainte-Cécile en décembre 1312, dans le même mouvement de nomination cardinalice que Jacques Duèze, le futur pape Jean xxII. Guillaume jouissait d'une expérience et d'une réputation assez larges, puisqu'il était à la fois un théologien reconnu (son commentaire sur les Sentences de Pierre Lombard, rédigé vers 1300 fut reconnu comme Lectura Thomasiana), un membre actif de l'ordre dominicain (prédicateur général de Narbonne en 1289, 
définiteur à Cahors en 1298, prieur provincial de Provence en 1301) et un curialiste (chargé en 1309 par Clément V de s'occuper du procès posthume de Boniface VIII). Jean XXII apprécia ses mérites puisqu'il le promut cardinal-évêque de Sabine en 1317, puis le désigna comme légat pontifical en Espagne de 1320 à 1324. De cette carrière, il ressort clairement que Guillaume de Peyre Godin n'avait aucune formation juridique et représentait la meilleure orthodoxie thomiste; le détail importe, car la tâche des inquisiteurs relevait davantage de la théologie que du droit. Guillaume n'avait pas été consulté en 1320 sur la question de la qualification hérétique des invocateurs du démon, peut-être parce qu'il était déjà parti en Espagne ; mais il reçut en 1326 une nouvelle commission pontificale, aux côtés des cardinaux Pierre d'Arablay et Bertrand de Montfavet, en vue de procéder aux procès de plusieurs clercs et laïcs des diocèses de Toulouse et Cahors accusés d'avoir fabriqué des images en plomb ou en pierre destinées à l'invocation des démons ${ }^{31}$. Les accusés avaient d'abord été convoqués devant la justice épiscopale de Toulouse avant d'être déférés au roi de France, probablement parce que leurs images avaient été fabriquées sur le modèle de la monnaie royale (sub figura seu typario regio) ${ }^{32}$. En 1328, Guillaume fut chargé de compiler l'enquête locale en vue du procès de canonisation de Nicolas de Tolentino; or cette affaire comportait de larges aspects démonologiques ${ }^{33}$.

19 À cette petite série, on peut ajouter une notation du dominicain Bernard Gui, qui, fort de son expérience d'inquisiteur, rédigea son Manuel de l'inquisiteur sans doute après 1324 : pour lui, l'invocation des démons relevait de l'hérésie si elle était faite « en même temps qu'un sacrifice ou que l'immolation d'une certaine chose en faisant offrande à ces mêmes démons par le moyen du sacrifice ou de l'immolation $»^{34}$.

Dix ans plus tard, le 4 novembre 1330, Jean xxII envoya deux lettres ${ }^{35}$, l'une adressée à l'archevêque de Narbonne, à ses suffragants et à l'inquisiteur de Carcassonne ${ }^{36}$, l'autre à l'archevêque de Toulouse, à ses suffragants et à l'inquisiteur de cette ville ${ }^{37}$ : cette lettre contenait une copie de celle envoyée en 1320 par Guillaume de Peyre Godin aux inquisiteurs de Carcassonne et Toulouse, puis ordonnait aux destinataires de poursuivre cette œuvre plus que jamais nécessaire ${ }^{38}$. Cependant, cette lettre introduisait un correctif important: les évêques devaient se mettre à l'œuvre, les inquisiteurs, seuls ou en collaboration avec les évêques devaient achever les actions entreprises, mais ces derniers ne devaient pas entamer de nouvelles procédures sans commission pontificale. Ce correctif n'enlevait rien à la qualification d'hérésie appliquée aux invocations démoniaques et autres formes de magie, puisque l'action inquisitoriale n'était pas suspendue ni simplement transférée aux évêques, mais il traduisait une certaine méfiance à l'égard des inquisiteurs, sur laquelle il faudra revenir.

Un mal ordinaire?

21 On peut se demander quel péril urgent se représentait le pape pour agir avec tant d'obstination. Les pratiques magiques, populaires ou savantes, que visaient les articles de la consultation de 1320 sont universelles et de tous les temps. L'envoûtement criminel ou amoureux par le biais d'images de cire ou de terre est bien attesté dans l'antiquité gréco-romaine (notamment sous le nom de defixiones) ${ }^{39}$. Quant au détournement magiques des objets sacramentaux chrétiens, il était largement attesté depuis fort longtemps ${ }^{40}$. Sous l'effet de la christianisation des mœurs, les vieilles traditions de magie naturelle et bénéfique se lestaient des rites liturgiques chrétiens, sans mutation réelle. 
Deux facteurs expliquent sans doute l'anxiété du pape. En premier lieu, la magie savante, importée de l'Orient ou de l'Espagne en même temps que la science naturaliste, avait connu un large développement dans les milieux savants depuis le début du xiII ${ }^{\mathrm{e}}$ siècle, comme l'atteste l'œuvre de Guillaume d'Auvergne. Des recherches récentes ont montré l'ampleur et la complexité de cette culture ${ }^{41}$. Les savoirs alchimique et astrologique, dotés d'un grand prestige scientifique, pouvaient se combiner à cette « négromancie » ou à ces arts de la magie. L'ambivalence des attitudes de l'Église vis-à-vis de l'alchimie commença à se défaire à la fin du XIII siècle $^{42}$, précisément au moment où les conquêtes de la science naturelle apparurent comme dangereuses pour la foi, tandis que l'astrologie conservait encore quelque légitimité, malgré les soupçons. On le sait, la fameuse condamnation prononcée en 1277 par l'évêque Étienne Tempier, qui, portait sur 219 propositions supposées être tenues par des membres de la Faculté des Arts, était précédée d'un prologue qui condamnait « les livres, rouleaux ou cahiers traitant de nécromancie ou contenant des expériences de sortilèges, des invocations des démons ou des conjurations au péril des âmes ${ }^{43}$. L'alchimie, protégée par les papes en quête de l'élixir de longue vie jusque dans les années $1270^{44}$, commençait, elle aussi, à devenir suspecte : comme le notait Agostino Paravicini Bagliani, le cardinal Francesco Orsini dans son testament de 1304, ordonna de brûler tous ses livres d'alchimie ${ }^{45}$. L'astrologie, malgré son allure plus académique, subissait les mêmes soupçons. Le destin tragique de Cecco d'Ascoli, qui fut un professeur d'astrologie respecté à Bologne à partir de 1322, avant d'être brûlé pour hérésie à Florence en 1327, en compagnie de ses livres d'astrologie, manifeste peutêtre, malgré son caractère singulier, cette ambivalence des attitudes; l'astrologie, en fait, malgré son statut de plus en plus suspect, vit son prestige s'accroître au cours du XIV ${ }^{\mathrm{e}}$ siècle.

23 L'affaire Robert de Mauvoisin, suivie de très près par Jean xXII, confirme cette ambivalence. Robert de Mauvoisin, archevêque d'Aix, fut jugé en 1318 par une commission pontificale et dut renoncer à son siège ${ }^{46}$. Le statut de cette poursuite est incertain, comme c'est souvent le cas dans ces commissions nommées directement par le pape : l'action fut, en fait, disciplinaire, mais elle aurait pu être criminelle, selon l'accentuation de tel ou tel délit, qui pouvait aussi bien relever de l'excès condamnable chez un prélat que du crime. Il est fort possible que cette qualification ait dépendu d'une négociation : le pape voulait récupérer le siège et Robert cherchait à se tirer de ce mauvais pas. Mais, quoi qu'il en soit, le premier des quinze articles d'accusation, le plus développé, joua un rôle certain dans la relative clémence de la commission; cet article rapportait que Robert depuis les temps de ses études à Bologne dans les années 1300 jusqu'au temps de sa prélature, avait eu recours « aux sortilèges, à l'art de la magie (arti mathematice) et aux divinations ». L'article précisait que ces pratiques étaient " condamnées et interdites par le droit ». Dans son interrogatoire, Robert prit soin de qualifier constamment ses différents conseillers d'«astrologues» et de relater précisément les modes et les buts de ses consultations. Tout en affirmant qu'il ne croyait pas en ces arts, Robert, confirmé par un témoin, maintint qu'il pensait de bonne foi que ces pratiques astrologiques étaient licites.

Or il semble bien que la méfiance nouvelle envers l'astrologie et l'alchimie, plus ou moins assumée par les savants et les hauts dignitaires de l'Église, se soit accompagnée, selon une causalité difficile à déterminer, d'une diffusion de la culture nécromantique et alchimique dans les couches plus basses de l'Église. Le second astrologue que Robert 
de Mauvoisin consulta pour évaluer son thème astral était un copiste (grossator) de la curie pontificale. Nous avons évoqué plus haut la poursuite de clercs et laïcs accusés de fabrication d'images sous l'effigie royale. Leur propre confession mentionnait explicitement l'usage de l'alchimie : il y est question de la recherche de la « vérité de l'alchimie » (veritatem alquimie).

À cette inquiétude générale et ambivalente, s'ajoutait le souci propre de Jean XXI qui paraît avoir considéré que les démons se mêlaient directement à ces arts suspects et exerçaient un rôle redoutable dans la vie et la mort des humains.

Les convictions démonologiques de Jean XXII

L'insistance de Jean XxII sur les dangers des invocations démoniaques correspond, dans la pratique judiciaire qu'il a développée, à de nombreuses accusations ${ }^{47}$ lancées à titre principal ou contre des accusés inculpés d'abord pour d'autres raisons, comme l'évêque de Cahors Hugues Géraud, l'archevêque d'Aix Robert de Mauvoisin, ou contre le franciscain Bernard Délicieux accusé d'entraver gravement le travail des inquisiteurs. Le parcours rapide de certains de ces dossiers nous aidera à saisir les préoccupations personnelles du pape en matière de magie et d'invocations démoniaques. Le 27 février 1318, Jean XXI s'adressa à Barthélemy, évêque de Fréjus, à Pierre Tissier, prieur de Saint-Antonin, près de Rodez, et au prévôt de Clermont-Ferrand, pour leur demander d'entreprendre une action selon la procédure sommaire et sans possibilité d'appel à l'encontre de plusieurs clercs qui s'adonnaient à «la nigromancie, la géomancie et autres arts magiques $»^{48}$. Ces arts de la magie sont étroitement reliés à l'invocation des démons; ils sont "des arts de démons, dérivés d'une pestifère association des hommes et des mauvais anges ». Les magiciens « usent fréquemment de miroirs et d'images consacrées selon leur exécrable rite et se plaçant en cercle, invoquent de façon répétée les démons. qu'ils enferment dans les miroirs, les cercles ou les anneaux ». Par ces invocations, les accusés tentent de nuire ou de prédire le futur ${ }^{49}$.

Or un autre aspect de leur activité, relevé dans la suite de la lettre, concerne un souci pontifical : «ils ne craignent pas d'affirmer qu'à l'aide de boissons ou de nourritures, mais aussi par la profération d'une seule parole, il est possible d'abréger ou de prolonger la vie des hommes ". On pense, bien sûr, aux différentes recherches et pratiques patronnées par les papes du XIII ${ }^{\mathrm{e}}$ siècle en vue d'obtenir le prolongement de leur vie, que les recherches d'Agostino Paravicini Bagliani ont repérées ${ }^{50}$. Le grand alchimiste anglais John Dastin, qui avait écrit des ouvrages d'alchimie pour le cardinal Napoléon Orsini, ennemi et familier du pape, envoya à Jean XxII une lettre sur l'or potable, susceptible de prolonger la vie ${ }^{51}$. Comme l'avait montré le procès de Boniface VIII, la frontière était incertaine entre les arts magiques et l'alchimie, entre le juste désir de prolonger la vie des papes et la sournoise volonté de l'abréger. L'octogénaire pontife, élu comme pape de transition, savait sa vie fragile et sa succession souhaitée. La première grande affaire judiciaire du pontificat, quelques mois après l'avènement de Jean XxII, mit en cause l'évêque de Cahors, Hugues Géraud, accusé d'avoir voulu attenter à la vie du pape et des cardinaux par le poison, mais aussi par la confection d'images de cire qui avaient reçu le nom des victimes et qui furent percées de coups d'aiguilles, selon l'évocation assez précise qu'en donne le pape dans sa lettre de commission de l'affaire le 22 avril $1317^{52}$. On comprend dès lors l'obsession de Jean XXII quant aux manipulations surnaturelles de la nature, d'autant que récemment certains alchimistes ou médecins, dont Arnaud de Villeneuve, avaient noué des 
relations fortes avec les Spirituels franciscains ou avec les clans Orsini et Colonna de la curie.

Le procès intenté au franciscain Bernard Délicieux en 1319 illustre bien cette conjonction. Bernard Délicieux était poursuivi essentiellement pour ses attaques contre l'inquisition et ses tentatives en vue du soulèvement des cités méridionales contre le pouvoir des inquisiteurs. L'affaire était déjà ancienne, mais le franciscain avait récemment aggravé son cas en prenant la défense des franciscains spirituels convoqués à Avignon en 1317. Or les articles 24 à 31 de son acte d'accusation portaient sur ses tentatives de meurtre sur la personne de Benoît XI, par le biais des incantations et des actes de magie ${ }^{53}$. Dans cette liste de griefs, pas plus que dans les accusations contre Robert de Mauvoisin, les pratiques magiques de Bernard Délicieux ne sont rapportées à une invocation des démons, comme si la magie naturelle n'était incriminée que pour ses fins mauvaises. Tout se passe comme si Jean XXII, héritier de la fascination de ses prédécesseurs envers la puissance des sciences occultes, hésitait encore à lier la magie à l'action démoniaque, ce qui expliquerait l'urgence et l'importance de la consultation de 1320.

Quelques années plus tard, ces incertitudes n'étaient plus de mise. Ainsi, le 23 août $1326^{54}$, le pape envoya une lettre au cardinal Bertrand de Montfavet l'incitant à poursuivre une enquête sur Bertrand d'Audiran, chanoine d'Agen qui se livrait à pluribus et diversis dampnatis scientiis et artibus " non sans une transgression de la foi catholique, du droit canonique et du droit civil ». Le suspect usait de livres, d'écritures, de vases de verre, de terre et de bois en lesquels il composait des poudres et liqueurs fétides. "Et surtout, ce Bertrand, en usant et abusant de ces sciences et arts, s'efforçait de tenter les démons et d'invoquer les esprits malins et d'appliquer à cette fin les conjurations et autres choses illicites et condamnées ». Or cette pratique était efficace : «il s'ensuivait de terrifiants coups de tonnerre, ébranlements, foudres, tempêtes, déluges, coups portés par les démons, agressions et morts d'hommes et autres innombrables dommages ».

Bertrand disposait de complices, dont deux sont nommés dans la lettre. Ils avaient été pris sur le fait quand ils emportaient sur des fourches patibulaires deux têtes et un bras de pendus. Le laïc avait avoué et avait été livré aux flammes; le clerc fut emprisonné dans les cachots de l'évêque d'Agen. L'évêque avait fait conduire Bertrand vers les prisons pontificales d'Avignon. L'enquête avait été confiée à Bertrand de Montfavet et au cardinal Pierre Tissier, mort depuis (en 1323). La lenteur d'une procédure qui était entièrement entre les mains du pontife montre bien que Jean XXII cherchait à savoir avant de réprimer.

Une autre lettre manifeste bien l'inquiétude de Jean xxII devant les mystères surnaturels et notamment devant la possibilité de transport extraordinaire, qui annonce peut-être un des aspects les plus spectaculaires du sabbat, le vol des démoniaques dans les airs. Le 3 mars 1325, Jean xxII s'adressa à l'évêque de Paris: le curé de la paroisse des Saints Innocents, un soir, a disparu de sa chambre fermée au verrou, de l'intérieur. Le pape demande une enquête summarie, simpliciter ac sine strepitu et figura judicii, afin de savoir "où ledit recteur est allé, ou a été emporté, ou transporté " (dictus rector iverit, vel asportatus aut translatus fuerit) ${ }^{55}$. Le ton pressé et angoissé de la lettre, l'évocation de la possibilité d'un transport surnaturel, sans évoquer vraiment le sabbat, manifestent, en cette mince affaire, une réelle inquiétude. 

des arguments produits par le pape pour prouver le caractère partiel et limité du jugement individuel consiste à insister sur l'activité libre des démons avant le Jugement dernier. En 1332, dans un sermon, le pape dit : «En effet, les damnés, c'est-à-dire les démons ne pourraient nous tenter s'ils étaient reclus en enfer. C'est pourquoi il ne faut pas dire qu'ils résident en enfer, mais bien dans la totalité de la zone d'air obscur, d'où leur est ouverte la voie pour nous tenter ${ }^{56}$.

Portrait de Jean XXII en suppôt du démon

XXII fut aussi acharné à poursuivre les démons et leurs adorateurs, c'est sans doute aussi parce qu'il fut lui-même parfois présenté comme une créature de l'Antéchrist ou du diable, notamment dans les divers milieux influencés par les franciscains spirituels (béguins, fraticelli). Cette qualification relevait en partie de l'injure, en partie de la conviction. En effet, d'un côté, les franciscains spirituels, adeptes de la plus haute pauvreté, qui avaient joui d'une relative tranquillité sous le pontificat de Clément $\mathrm{V}$, subirent la répression violente de Jean XxII, dès le début de son pontificat : quatre franciscains spirituels furent brûlés à Marseille en 1318 ; une série de bulles, de 1317 à 1328, condamnèrent certains groupes, puis la doctrine même de la pauvreté absolue et de son fondement christique. On en arriva au schisme de 1328, quand Michel de Césène et quelques frères s'enfuirent d'Avignon pour rejoindre la cour de l'empereur Louis de Bavière, qui créa le bref pontificat schismatique de Nicolas V. Dans la masse des écrits de combat des franciscains, le pape prit souvent une figure satanique.

Mais il y avait plus. Dans les écrits de Pierre de Jean Olivi, qui fut l'inspirateur principal de ces mouvements, se manifestait la conviction que le temps présent était celui du passage à la sixième période de l'histoire de l'Église, lui-même annonciateur du troisième et dernier âge de l'humanité. En lisant l'Apocalypse, Olivi avait découvert que l'Antéchrist, dont la défaite ultime devait ouvrir une longue période de paix avant la fin des temps, se dédoublait en un Antéchrist «mystique » (c'est-à-dire caché) et le grand Antéchrist manifeste. Cet Antéchrist mystique devait probablement être un pseudopape. Si Olivi, mort en 1298, n'avait pas poussé plus loin l'identification, ses disciples, confirmés par les persécutions, procédèrent à cette assimilation du pape à l'Antéchrist mystique.

Sur ce point, un témoignage curieux livre un véritable récit fondateur et mythique sur les origines de la haine de Jean XxII contre les spirituels franciscains. En 1333, le chevalier roussillonnais Adhémar de Mosset fut poursuivi pour ses sympathies béguines, à l'initiative du roi Jacques II de Majorque ${ }^{57}$. Le roi, dans son troisième article d'accusation, rapporte un souvenir personnel. Un jour qu'il voyageait en compagnie d'Adhémar, la conversation vint sur le pape Jean xxII et sur les persécutions contre les spirituels, que le chevalier reprochait fort au pontife. Adhémar demanda au roi s'il savait pourquoi le pape, qui au début de son pontificat avait été une homme saint et bon en était arrivé là. Jacques ne le savait pas, mais le chevalier le lui apprit : Jean XxII aimait alors beaucoup Angelo Clareno, l'un des principaux dirigeants des spirituels. Un jour, il lui demanda d'interroger Dieu, pour savoir si son état (status) Lui plaisait ou non $^{58}$. Angelo se mit en prières et « vit alors une grande foule de diables qui portaient un calice plein du poison d'iniquité ; il leur demanda où ils allaient et ce qu'ils allaient faire de ce calice. Ils lui répondirent qu'ils allaient auprès du pape, pour faire leur possible afin qu'il boive le calice d'iniquité. » Angelo leur demanda de passer le voir sur 
le retour, ce qu'ils firent. Ils lui apprirent alors que le pape avait bu et ils conseillèrent à Angelo de se garder désormais de lui. Au sortir de cette vision, le pape demanda à Angelo le résultat de sa consultation; le franciscain refusa de parler, mais reçut l'ordre, au nom du principe d'obéissance, de livrer ses informations, ce qu'il fit. «Et depuis ce temps là le seigneur pape lui voulut du mal, à lui et aux autres Béguins. » Adhémar de Mosset, qui avait été au service de Philippe de Majorque, régent du royaume sous la minorité de Jacques II et partisan actif des Béguins, était probablement un sympathisant des dissidents, sans être directement engagé dans leur combat et sans avoir de formation théologique ni exégétique; il est probable qu'il transmettait une anecdote largement répandue. Si l'on perçoit mieux le développement d'un engagement personnel du pape, il reste à comprendre les modalités de sa lutte.

Le positivisme de Jean XXII

Pourquoi qualifier d'hérésie la magie, ou l'invocation des démons? Parce que les adorateurs des démons produisent de nouveaux faits, susceptibles d'engendrer de nouvelles adhésions. Il faut insister sur cette notion de factum hereticale, brandie dans les questions posées aux théologiens en 1320, qui rompt avec l'idée commune de l'hérésie comme opinion ou comme intellectus. Il ne s'agit pas seulement d'une extension qui trouverait dans les pratiques sacrilèges un fondement doctrinal. Jean XXII n'avait nul besoin de cette qualification pour réprimer sévèrement les actes magiques et démonolâtriques.

Le pape croyait en la force des faits, en droit comme en théologie. Ainsi, en mai 1330, il s'adressa au roi de France pour lui demander d'interdire la pratique de la preuve par combat judiciaire ou due ${ }^{59}$ en notant que «par de telles pratiques, la vérité n'est pas prouvée » (per talia...veritas non probatur). Le pape, au nom de l'expérience maîtresse des choses (magistra rerum experiencia) fait remarquer au roi qu'en cas d'accusation de fausse monnaie, jamais le souverain ne se contenterait d'une telle preuve, précisément parce qu'en ce cas, les faits matériels et la vérité pure importent.

La construction même de faits inédits est une menace pour la foi. Car ce sont les faits qui induisent la confiance et la foi. La qualification traditionnelle de l'hérésie, en s'en tenant au rejet des opinions orthodoxes, ne considère pas le processus qui conduit à la foi. Devant l'extrême diversité des opinions et des écoles, il faut s'en tenir aux faits. Jean xxII, exactement comme Guillaume d'Ockham, aboutit à la conclusion que la foi repose sur une certaine confiance accordée à l'ensemble de la tradition chrétienne et corroborée par les faits livrés par l'Écriture. La foi repose sur un contrat de confiance. Un des reproches les plus véhéments qu'il adresse aux franciscains, c'est de piétiner les données factuelles de l'Écriture. Dans l'Évangile, Jésus a possédé des biens et a confié sa bourse à Judas. Or, par des artifices d'interprétation, ils anéantissent ces faits, au bénéfice de leur interprétation. Les grandes bulles de condamnation de la doctrine franciscaine de la pauvreté absolue insistent sur cette destruction des données factuelles qui fondent les articles de foi ${ }^{60}$. Dans la bulle Cum inter nonnullos (12 novembre 1223), le pape disait :

L'affirmation selon laquelle le Christ et les apôtres n'ont rien possédé ni en commun, ni individuellement, nous jugeons par un édit perpétuel et en suivant l'avis de nos frères que, quand elle est répétée avec obstination, elle doit être tenue pour erronée et hérétique, car, comme elle contredit expressément l'Écriture sacrée, qui en plusieurs lieux affirme qu'ils ont eu quelque possession, elle implique que cette Écriture sacrée, par laquelle sont prouvés les articles de la foi orthodoxe, contient ouvertement, sur ce sujet, le germe du mensonge et que, en tant que telle, 
elle évacue toute confiance en l'Écriture et rend la foi catholique douteuse et incertaine en supprimant sa force probatoire. ${ }^{61}$

Plus généralement, les franciscains spirituels, en imaginant que le Christ et les apôtres pratiquaient un usage "de fait », sans aucune appropriation juridique, construisaient une fiction qui ne trouvait aucun répondant, aucune vérification dans la « nature des choses " (natura rerum), où la consommation des biens repose soit sur un droit, soit sur un délit. Leur usage du mot "fait» renversait l'ordre naturel du monde. Les franciscains devenaient hérétiques en rejetant les faits évangéliques et en reconstruisant leurs propres faits, grâce à leur idéologie forte et grâce à l'identité collective qu'ils créaient. Les adorateurs des démons n'agissaient pas autrement, on le verra.

Donc, pour Jean XXII, un fait est un fait. Comment comprendre ce positivisme, qui semble anachronique, sans le réduire aux fantaisies singulières du vieux pontife?

L'émergence du fait

Pour saisir ce tournant, il faut sans doute partir du jugement moral, et non pas $d u$ jugement épistémologique, des conduites humaines plus que des processus physiques. Chacun le sait, le XII ${ }^{e}$ siècle, entre Pierre Abélard et Pierre le Chantre a produit une morale de l'intention. Mon hypothèse est que c'est cette morale qui a construit la notion de fait, en neutralisant l'événement. Jean est tué. Paul l'a tué. Ceci est un événement. La théologie morale de l'intention affirme que cet événement ne signifie rien en lui-même, avant qu'il ne soit qualifié selon l'intention de Paul, qui construit l'événement comme meurtre (il a voulu et prémédité cet acte, par l'effet d'une vieille haine), ou bien comme coups et blessures portés sans intention de meurtre (à la suite d'une rixe, par exemple), comme accident (Paul au cours d'une chasse, visait un gibier), comme acte méritoire (Paul a débarrassé la chrétienté d'un persécuteur, sur le modèle de Judith tuant Holopherne). L'événement "mort de Jean ", vidé de sa signification intrinsèque, devient ce que j'appelle un fait faible, un résidu irréductible de réalité.

d'Abélard doit se relier étroitement au principe naissant de l'enquête contradictoire. Le premier texte qui proclame la nécessité de cette enquête se trouve dans la préface du Sic et non. On sait que cet ouvrage, en dehors de sa préface, ne contient que des citations contradictoires sur une série d'objets, mais on n'a pas relevé que ces objets ne sont pas toujours des opinions théologiques, mais aussi des faits (comme, par exemple, l'emplacement géographique de la tombe des patriarches).

$\mathrm{Au}$ cours du XIII ${ }^{\mathrm{e}}$ siècle, se produisit une réaction progressive contre la morale de l'intention, une tentative d'objectivation du jugement moral et judiciaire. Ce phénomène tient probablement au mouvement de rédaction des textes normatifs et à la constitution du droit comme science de plus en plus indépendante de la théologie morale ${ }^{62}$. Le fait fut pensé comme un résidu nécessaire à l'indépendance transcendante $\mathrm{du}$ droit, que la caste des juristes tentaient d'extraire des contingences et des compromissions des affaires courantes. Mais l'attachement à la factualité tenait aussi à une réaction de l'Église contre les entreprises hérétiques appuyées sur une pratique du secret et de la double entente. Le sanctuaire de l'intériorité pouvait apparaitre comme une cache de malfaiteurs. Les poursuites contre les cathares et les béguins le montrent clairement: les inquisiteurs mirent au point des techniques de repérage de la dissimulation. Cette évolution tendait donc à remplacer le fait faible des morales de l'intention par le fait fort des tribunaux d'enquête. Est-ce à dire qu'au tribunal toute excuse quant à la circonstance de l'action était rejetée? Certes pas, mais les 
circonstances furent elles-mêmes objectivées. On en donnera deux exemples : la notion d'irresponsabilité, accordée à des classes repérables d'individus (les fous, les enfants, les somnambules) fut définie au début du XIV ${ }^{e}$ siècle par une décrétale de Clément $\mathrm{V}^{63}$. Par ailleurs, dans la procédure inquisitoire, l'enquête préalable sur la réputation (fama) des individus suspects déléguait à une communauté extérieure l'évaluation des motifs, avant que l'enquête en vérité ne mette en corrélation cette évaluation avec des faits précis. Certes, la fama fut largement induite par les poursuites elles-mêmes, mais les juges tenaient à son caractère objectif et mesurable. Dans les procès inquisitoires, en canonisation comme en matière criminelle ou hérétique, les juges ou commissaires demandent fréquemment aux témoins de définir le sens du mot fama, son lieu d'origine, son extension. Certains allaient même jusqu'à demander au témoin d'évaluer quantitativement le nombre minimal d'opinions ou de murmures nécessaires pour constituer une réputation.

Ce positivisme médiéval, dont nous avons tenté de repérer les racines juridiques et morales, peut-il être relié à une évolution plus globale que l'on pourrait saisir dans l'histoire des sciences? La question est délicate, car la physique dominante, inspirée d'Aristote, s'attachait davantage aux causes qu'aux phénomènes, comme l'a montré Alexandre Koyré. Le phénomène était essentiellement réductible. Pourtant, un certain développement de la factualité scientifique s'observait précisément en ces dernières années du XIII ${ }^{\mathrm{e}}$ siècle, soit du côté des ingénieurs comme le célèbre Pierre de Maricourt, qui décrivait et expérimentait les propriétés de l'aimant en vue de l'amélioration de la boussole. Un grand penseur comme Roger Bacon, grand chantre de l'expérimentation, réussissait à conjoindre dans son œuvre, la théologie, l'optique et l'alchimie en traquant des faits par l'observation. La catégorie fourre-tout des "merveilles" (mirabilia) commençait à s'étioler au profit d'une extension simultanée des phénomènes miraculeux et des phénomènes naturels. Enfin, une physique non-aristotélicienne, raisonnant sur des cas-limites, relevant d'une factualité réelle, mais rare, se mettait en place $^{64}$.

L'enquête et le fait

Sur le plan des poursuites judiciaires, la notion de fait tendit à s'imposer, quand, à partir des années 1230 , la recherche des hérétiques, au sein de populations largement complices, prit un caractère massif et exigea des critères plus larges et des méthodes plus efficaces que l'interrogatoire individuel. Un mandement de l'archevêque de Tarragone fut rédigé en mai $1242^{65}$ avec l'aide du dominicain Raymond de Penyafort, le grand juriste qui devint aussi maitre général de l'ordre des prêcheurs afin "que l'on procède plus clairement quant au fait d'hérésie (circa factum heresis) ». Certes, le mot factum a encore ici le sens d'imputation judiciaire qu'il avait dans le droit romain, mais le détail du mandement montre bien qu'il importait désormais de considérer des actes qui ne relevaient pas directement de la croyance. Le texte, en effet, distingue sept classes de population reliées à l'hérésie ${ }^{66}$. Or seule la première est nommé hérétique, parce qu'elle professe des croyances en perdurant dans l'erreur. La seconde catégorie, les « croyants " (credentes), est assimilée aux hérétiques (il faut sans doute comprendre qu'ils sont mis à part avant l'avertissement salutaire qui les transforme, en cas de refus d'abjurer, en hérétiques proprement dits). Ensuite viennent les « suspects " d'hérésie. Seuls des actions et des faits construisent cette qualification : écouter la prédication ou les conférences des hérétiques (en ce cas il s'agit d'insabbatici, hérétiques difficiles à identifier et qui sont cités en compagnie des Pauvres de Lyon et des Vaudois), 
s'agenouiller en leur compagnie. Un élément de croyance peut pourtant être ajouté : les suspects croient que les hérétiques en question sont de "bons hommes». Suivant la répétition des actes, la suspicion sera simple, véhémente ou très véhémente. Viennent ensuite les complices passifs : les «non-dénonciateurs » (celatores) qui s'abstiennent de révéler la présence publique d'hérétiques, les « dissimulateurs » (occultatores), « qui ont fait pacte de ne rien révéler" (fecerunt pactum de non revelando), les "hôtes" (receptatores), qui reçoivent chez eux, au moins deux fois des hérétiques ou des réunions d'hérétiques, les « défenseurs " (defensores) qui prennent le parti des hérétiques par la parole ou par le fait (verbo vel facto), soit par le discours, soit par une aide matérielle ${ }^{67}$. Ces quatre dernières catégories sont rassemblées sous la qualification de "soutiens " (fautores) de l'hérésie. Les délits liés aux hérésies sont, pour Raymond, susceptibles de degrés (magis vel minus), alors que l'hérésie proprement dite implique une structure strictement binaire, où le vrai s'oppose à l'erreur. Là encore, c'est le droit qui construit, par opposition, le fait: par opposition au ministère du confesseur qui, in foro conscientiae, traite le continuum des fautes et manquements, la tâche de l'inquisiteur in jure consiste à réduire à la pureté binaire de l'incrimination, une foule de circonstances et d'action floues. Plus tard dans le siècle, la notion de " présomption de droit » accrut encore cette tendance.

Mais l'hésitation est encore grande : le quatrième point de la consultation porte sur la qualification comme hérétique de celui qui embrasse un hérétique, ou qui prie en sa compagnie ou le cache : « doit-il être jugé comme croyant en l'erreur de l'hérétique?» La réponse était négative. Pourtant, plus loin, le texte suggère que les ossements de ceux qui ont soutenu l'hérésie doivent être exhumés, parce que «le soutien (fautoria) est la suite et le complément de l'hérésie ». Quelques années plus tôt, en 1235, dans un des premiers textes consacrés aux règles de l'inquisition, Raymond de Penyafort considérait que ceux qui hébergeaient des hérétiques (en l'occurrence des Vaudois) devaient être jugés comme hérétiques, parce qu'ils croyaient que l'Église se trompait en poursuivant les hérétiques ${ }^{68}$.

On le voit, la tentation était grande, depuis les débuts de l'inquisition, de construire des faits hérétiques. Lorsque, le 14 juin 1303, Guillaume de Plaisians présenta au Louvre ses accusations contre le pape Boniface viII, il lui reprocha d'avoir extorqué à des prêtres la révélation de secrets confiés en confession pour les divulguer et les utiliser. Il conclut cet article en disant: "En raison de cela il semble avoir été hérétique quant au sacrement de pénitence (propter quod in sacramento penitentie hereticare videtur). »C'est donc bien un acte, manifesté par le verbe actif "hérétiquer" qui passe pour manifestation d'hérésie. Comme le note Jean Coste dans son édition du "procès », le cardinal Pietro Colonna, qui connaissait mieux le droit canonique, avait ajouté dans la rédaction d'un article analogue: «le même Boniface proclamait de façon doctrinale (dogmatizabat) qu'il avait le droit d'agir ainsi. " ${ }^{69}$

En 1308-1309, l'auteur d'une nouvelle série d'articles d'accusation contre la mémoire de Boniface, que Jean Coste attribue à Nogaret ${ }^{70}$, introduit une distinction alors inédite, qui fut reprise cinquante ans plus tard par Nicolas Eymerich ${ }^{71}$, entre les articles hérétiques, les erreurs relatives à un point de fait déjà condamné (facti damnati errores) et les opinions. Mais la simple mention de cette distinction, sans application précise, ne permet pas de considérer que la notion de «fait hérétique» se développait véritablement. 
50 Les juges délégués au procès de Bernard Délicieux, en 1319, franchirent ce pas, du moins dans leur acte d'accusation du 23 octobre 1319 : ils ouvraient leur accusation en déclarant, sur un ton très législatif, mais sans aucune allégation de droit que tout homme, seigneur, puissant ou juge qui oserait libérer les prisonniers de l'inquisition, refuser d'exécuter ses mandats, empêcher la sentence ou le procès, ou s'opposer en quelque façon à la poursuite des hérétiques, "encourt ipso facto une sentence d'excommunication et s'il l'encourt avec une volonté résolue pendant un an, est alors condamné comme hérétique $»^{72}$.

Questions de procédure

51 Face à la menace démoniaque, il importait d'agir efficacement et rapidement ; mais ces deux exigences étaient contradictoires, car l'efficacité supposait le lent et difficile établissement de la vérité. Le pontife disposait d'une multitude de solutions judiciaires qui impliquaient à la fois des différences dans les types de procédure, dans les ressorts juridictionnels et dans les modalités de l'enquête.

52 L'Église favorisait le développement de la procédure inquisitoire (par enquête), au détriment $\mathrm{du}$ mode accusatoire, selon un mouvement initié par des décrétales d'Innocent III, à partir de 1198, dont la maturation se lit dans le canon 8 du concile de Latran IV (1215). On le sait, la procédure accusatoire, dominante jusqu'au XII ${ }^{\mathrm{e}}$ siècle, et qui a poursuivi sa carrière dans la Common Law britannique et américaine, réserve l'incrimination à un accusateur, qui s'engage sur cette accusation et peut en pâtir. Le juge ou le jury se contente d'arbitrer. Les deux moments de l'action sont constitués par la construction minutieuse de la cause, qui doit être rigoureusement définie (en termes romains, il s'agit de la phase de litis contestatio) et par la délibération. La procédure inquisitoire, en revanche, favorise l'accusation d'office, formulée par un juge ou un prince, à la suite d'une "diffamation", dérivée de l'écoute d'une rumeur accusatrice. Le procès met en œuvre deux enquêtes successives : la première établit cette fama, cette réputation, bonne ou mauvaise, qui permet l'inculpation ou la relaxe; la seconde enquête construit la vérité des faits portés par la fama.

Plusieurs ressorts juridictionnels pouvaient prendre en charge les invocateurs du démon : la justice épiscopale, avec ses divers tribunaux, le tribunal de l'inquisition et des commissions pontificales ad hoc. L'inquisition fut créée par le pontificat à partir de 1233, en vue de poursuivre l'hérésie et elle garda longtemps cette spécialisation, qui impliquait un recrutement de juges plus théologiens que juristes. Il est difficile de porter un jugement serein sur l'inquisition médiévale, tant son image a fait l'objet de controverses violentes. Certains médiévistes ont tenté, non sans quelques raisons, de rejeter la folie persécutrice associée à cette image. Edward Peters a montré comment avait pu se construire dans la suite des temps un véritable mythe noir de l'inquisition ${ }^{73}$; un article retentissant de Richard Kieckhefer a mis en doute la réalité institutionnelle de l'inquisition ${ }^{74}$. De fait, l'opinion commune a souvent confondu les réalités implacables de l'Inquisition romaine (créée en 1542) et surtout de l'Inquisition castillane (institution étatique fondée en 1481-1482) avec les tentatives limitées et souvent incohérentes de l'inquisition médiévale. Pourtant, l'inquisition médiévale a bien existé comme institution puissante, en dépit de sa faible assise. L'inquisiteur était nommé par le saint Siège, mais demeurait étroitement lié à l'ordre religieux dont il provenait (l'ordre dominicain pour l'essentiel, mais aussi l'ordre franciscain, et, dans une moindre mesure, l'ordre des carmes). Sa pratique quotidienne le mettait en relation étroite avec le pouvoir séculier. 
54 pontifes, instaurée depuis le $\mathrm{xII}^{\mathrm{e}}$ siècle, mais elles prirent une importance particulière sous le pontificat de Jean xxII, pour des raisons que nous examinerons plus loin. L'importance des faits démoniaques conduisit Jean XXII à lever beaucoup de garanties judiciaires et gracieuses ${ }^{75}$ et à confier les affaires de complot avec soupçons magiques ou démonologiques à des commissions pontificales, qui se réclamaient de la procédure sommaire. La notion de procédure sommaire s'est lentement développée depuis la fin $\mathrm{du} \mathrm{XII}^{\mathrm{e}}$ siècle dans le droit canonique. Il s'agissait de formaliser les efforts des décennies précédentes en matière d'arbitrage ou de compromis internes à l'Église, en réaction aux excès de juridisme qui avaient été dénoncés par saint Bernard dans son retentissant traité De consideratione. La notion d'« équité canonique » était opposée à la rigor iuris des civilistes. La procédure trouva lentement sa forme à partir d'éléments épars dans le droit romain, par agglomération de clausules indépendantes: si les parties étaient d'accord, la cognitio summaria (traduite dans nos textes par l'adverbe summarie ou simpliciter) impliquait d'alléger les charges de preuves; on pouvait se contenter de preuves «semi-pleines » (un simple serment, un témoin ou un document unique), et de la phase proprement procédurale d'un procès; la rédaction d'un « livret » (libellus) et le débat de la litis contestatio (qui établissait les rôles judiciaires et les enjeux du procès) devenaient facultatifs. La mention d'une procédure de plano, qui renvoyait à l'inutilité de siéger formellement en tribunal insistait davantage sur la rapidité et l'absence de formes externes. Enfin les clausules sine strepitu judiciorum (sans le vacarme des procès) et sine figura judicii (sans la forme du procès) complétaient cette simplification en insistant sur la suppression des avocats et des formes bruyantes d'opposition et de recours.

55 À l'époque de Jean XxII, cette formalisation de l'arbitrage ecclésiastique venait à peine de s'achever, par la publication de deux décrétales de Clément V, Dispendiosam produite pour le concile de Vienne en 1311-1312 et Saepe, rédigée en 1314. Dispendiosam ${ }^{76}$ déclarait de façon fort brève que la procédure sommaire pouvait s'appliquer d'une part aux cas déjà prévus par le droit canonique du XIII ${ }^{e}$ siècle quant aux affaires propres de l'Église (« élections, demandes et provisions, attributions de dignités, de fonctions, de charges, de canonicats, de prébendes et autres bénéfices ecclésiastiques » et contentieux sur les dîmes), mais aussi sur les questions de mariage et d'usure. Cette extension était considérable et aboutissait à fournir la possibilité de procédure sommaire pour la quasi totalité des affaires évoquées par l'Église. Seules les successions n'étaient pas mentionnées, mais elles interféraient nécessairement avec les causes matrimoniales. La décrétale Saepe $e^{77}$ détaillait plus longuement les particularités de la procédure sommaire et résumait soigneusement les traits assemblés depuis près d'un siècle.

L'usage parallèle de la procédure sommaire en matière de poursuite de l'hérésie ne se laisse pas facilement déchiffrer, car la filiation par rapport à la doctrine de l'arbitrage y perd tout sens. Le seul point commun des deux usages tient au rôle essentiel du juge, chargé à la fois de la procédure, de l'instruction et de la décision. Pourtant, ce n'est pas avant la décrétale Statuta quedam, promulguée par Boniface VIII dans son Liber Sextus en 1296-1298, que la procédure sommaire fut accordée explicitement à la procédure inquisitoriale: «En collationnant certains statuts de nos prédécesseurs d'heureuse mémoire Innocent, Alexandre et Clément, et en interprétant et ajoutant certains points, nous accordons que dans les affaires d'inquisition sur la perversion hérétique, il 
puisse être procédé de façon simple et informelle, sans vacarme ni apparence des avocats et des jugements (procedi possit simpliciter et de plano, et absque advocatorum ac judiciorum strepitu et figura) ». La suite de la décrétale justifie le secret sur les noms des témoins ou accusateurs, pour raison de sécurité.

Procès et majesté

Tous les niveaux et distinctions que nous venons d'esquisser se mêlaient dans la pratique judiciaire, puisque l'inquisition se fondait largement sur la procédure inquisitoire, tandis que des évêques, comme Jacques Fournier, le célèbre évêque de Pamiers, ou Guido Terreni, évêque de Majorque, puis d'Elne recevaient du pape des fonctions d'inquisiteur dans leur diocèse.

Pourtant, Jean XXII n'avait guère confiance dans la justice des évêques. Il savait que les évêques pouvaient souvent préférer la paix du diocèse à l'exigence de la vérité. Ainsi, à l'efficace et zélé Jacques Fournier avait succédé, en 1326, Dominique Grima, brillant théologien, ancien assistant inquisiteur de Bernard Gui à Toulouse, qui s'attira le courroux du pape pour sa négligence dans la poursuite de l'hérésie ${ }^{78}$. Le pape préféra fréquemment utiliser des commissions spéciales d'enquête et de jugement selon la procédure sommaire, plutôt que les tribunaux inquisitoriaux. Ce fut le cas, notamment pour les procès de Hugues Géraud, de Robert de Mauvoisin et de Bernard Délicieux. Parfois l'imputation de crime de lèse-majesté permit de donner une latitude encore plus large aux procédures extraordinaires : ainsi, le 12 avril 1331, sur plainte du roi de France, le pape ordonna à l'évêque de Paris de procéder contre Hertaud, abbé d'un monastère du diocèse d'Autun et contre Jean Albéricus, dominicain sur leurs "maléfices et excès " (super maleficiis et excessibus) contre le roi et sa cour ». Il s'agit certainement de pratiques magiques (multis maleficiis) qui attentaient au "salut public » et qui, en tout cas, relevaient du crime de lèse-majesté. Or le pape, en ce cas, non seulement ordonna une procédure sommaire (simpliciter, et de plano sine strepitu et figura judicii), mais leva tous les privilèges et garanties des deux religieux, autorisant leur arrestation (captionem), leur incarcération et leur torture (necnon questionibus subici prout a canonibus est permissum) ${ }^{79}$.

On peut se demander pourquoi Jean XXII fut si réticent à confier les causes démoniaques à l'inquisition, au moment même où il tentait d'assimiler l'invocation des démons à l'hérésie. La réponse la plus commune à cette question relie ce choix au caractère politique de bien des affaires où le démon semble intervenir comme prétexte, plutôt que comme cause. De fait, les procédures exceptionnelles qui mêlent l'attentat contre la majesté royale ou divine, les accusations d'hérésie et les imputations de sorcellerie ou d'invocation des démons doivent être reliées à la grande vague des procès politiques,

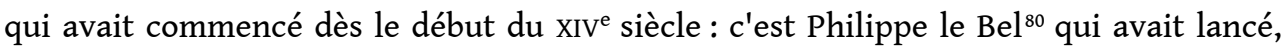
dès 1303 , le procès contre le pape Boniface vIII ${ }^{81}$, accusé, entre autres, d'avoir invoqué les démons et consulté des magiciens ; puis le roi, entre 1306 et 1314, s'en était pris aux Templiers comme adorateurs du diable. Entre 1308 et 1314, Philippe le Bel avait inculpé Guichard, évêque de Troyes, qui aurait conspiré en vue de tuer la reine et d'autres personnalités princières par l'usage de poisons et d'images magiques ${ }^{82}$. En 1315 , Enguerrand de Marigny, qui avait si efficacement collaboré à ces procès, fut lui-même pendu pour avoir nui au roi Louis X et à Charles de Valois par des images magiques ${ }^{83}$. Jean XXII prit le relais, avec les procès contre Hugues Géraud, évêque de Cahors ${ }^{84}$ en 1317, contre Mateo et Galeazzo Visconti en $1320^{85}$, contre les alliés de Federico de Montefeltro dans la Marche d'Ancône ${ }^{86}$. Dans tous ces cas, la parfaite correspondance 
entre la gravité des accusations et la position antagoniste des inculpés incite à voir dans ces procès de simples et cyniques manœuvres, où l'exception judiciaire doit confirmer la règle politique.

60 Cette interprétation rend imparfaitement compte des réalités; l'écrasement des adversaires ne fut pas systématique : les graves accusations contre Bernard Délicieux quant au meurtre démoniaque de Clément $\mathrm{V}$ ne furent pas assumées dans le jugement, contrairement à ce qui se passa pour Hugues Géraud. Robert de Mauvoisin s'en tira avec une simple éjection de son siège archiépiscopal. Certes, les juges avaient quelque autonomie, mais on peut penser que le pape avait éprouvé de réels doutes quant à la culpabilité des accusés. Ces interrogations rendent peut-être compte de la consultation de 1320, qui relevait moins de la discussion quodlibétale ou de la collégialité de décision que du besoin d'expertise.

Méfiance de l'inquisition

61 Les choix de procédure de Jean XXII doivent s'expliquer autrement. La préférence pour la forme extraordinaire tient d'abord à une grande méfiance de l'inquisition. Les inquisiteurs avaient tendance à poursuivre sans tenir compte des rangs sociaux ni des circonstances politiques : la fameuse affaire de Jean l'Archevesque, sieur de Parthenay, mêlé à des pratiques de sortilège vers 1323 le montre bien. L'inquisiteur s'était attaqué à un personnage puissant, bénéficiant de protections royales, qui avait réussi à obtenir la consultation d'un grand juriste, Oldrado da Ponte ${ }^{87}$. À deux reprises, le pape écrivit aux inquisiteurs de Carcassonne pour leur enjoindre de ne pas tourmenter inutilement les consuls et bourgeois de Montpellier ${ }^{88}$.

62 Le pape avait pu aussi éprouver l'extrême impopularité de l'inquisition, patente dans l'affaire Bernard Délicieux: un simple agitateur avait failli renverser le pouvoir monarchique français en liguant les couches citadines hostiles à l'intervention des inquisiteurs. En 1317-1318, c'est le zèle excessif de Michel Le Moine, inquisiteur franciscain de Provence qui avait enflammé la résistance béguine dans le Midi par l'exaltation des martyrs de Marseille. En 1321-1322, c'est le manque de discernement de l'inquisiteur Jean de Beaune à Béziers qui avait entraîné le pape sur un terrain imprévu. L'inquisiteur ne mesurait pas toujours la portée de ses actes et surtout il pouvait agir trop publiquement du moins dans la phase initiale (la proclamation de l'enquête) et dans sa phase conclusive (le sermon général) : ainsi, c'est la dispute publique entre l'inquisiteur de Carcassonne Jean de Beaune et le lecteur franciscain du couvent de Narbonne, Béranger Talon, qui avait provoqué la reprise du débat sur la pauvreté du Christ. Enfin et surtout, l'inquisition jouissait d'une certaine indépendance par rapport au pouvoir pontifical : d'une part sa nomination dépendait aussi du bon vouloir du maitre général des dominicains ou du ministre général des franciscains. D'autre part, il pouvait, à l'occasion se rapprocher du pouvoir royal. On peut se demander si la différence de dénomination des inquisiteurs de Carcassonnne et de Toulouse, entre 1320 et 1330, dans les lettres citées plus haut rédigées par Guillaume de Peyre Godin puis par le pape, ne traduit pas cette perception: dans le premier cas, le cardinal s'adresse "à l'inquisiteur de la perversion hérétique de la région de Carcassonne "; dans le second cas, il s'agit de «l'inquisiteur de la perversion hérétique député par le Siège apostolique dans le royaume de France, en résidence à Carcassonne. » Le soin de cette seconde formulation insiste sur le fait que l'origine du pouvoir inquisitorial se trouve bien dans le pontificat. De fait, l'inquisition méridionale, après les froissements dûs à l'affaire Bernard Délicieux, où les officiers royaux avaient toléré ou même 
soutenu le trublion franciscain, avait été largement instrumentalisée par la monarchie, comme le montrait l'affaire des Templiers.

En outre, le pontife était fort irrité du manque de respect de certains inquisiteurs pour le droit. Ainsi, en 1331, il reçut et approuva les plaintes de maître Jean Anselme de Gênes, chirurgien, et de Réginald de Cravant, clerc du diocèse d'Auxerre, qui avaient été faussement accusés d'hérésie et de maléfices par l'inquisiteur de France Aubert de Châlons et par l'évêque de Paris Hugues Michel de Besançon. Le pontife leur reprochait d'avoir agi sans avoir établi aucune infamie antérieure, sans respecter l'ordre judiciaire, sans permettre aucune défense légitime ${ }^{89}$. Il n'est pas besoin d'imaginer un Jean XXII soucieux de justice par formation professionnelle : comme on l'a vu, l'ordre du droit permettait d'établir soigneusement la vérité, qui importait bien davantage que la répression. Le cas de la censure du commentaire d'Olivi sur l'Apocalypse le montre bien : le texte était dangereux, puisqu'il inspirait directement les Béguins par le biais d'abrégés et de traductions en langue vernaculaire. Le contenu anti-pontifical de ce texte était manifeste. Pourtant le pape usa, directement ou indirectement, de quatre commissions différentes, durant huit ans (1318-1326), avec un supplément d'enquête en 1322, avant d'arriver à une condamnation. Le résultat répressif était certainement acquis dès 1318, mais il importait de suivre minutieusement les chemins de l'erreur. Ce souci apparaît clairement dans une lettre adressée par le pape en 1330 à Henri Chamayou, inquisiteur de Carcassonne ${ }^{90}$, qui avait réussi à faire arrêter deux hérétiques italiens, qui avaient confessé leur crime. Le pontife félicite chaleureusement l'inquisiteur, mais l'engage fermement à poursuivre l'enquête, bien qu'il ait déjà en main tous les éléments pour les condamner : « parce que nous croyons que tu aurais du connaître une vérité plus ample (novisse te plenius credimus veritatem) au sujet de ce pour quoi ils t'ont été livrés, nous voulons et il nous plaît qu'ayant Dieu seul devant les yeux, tu veilles, selon l'exigence de la justice, à ne pas négliger ce que tu sauras être adéquat en cette affaire ».

64 Ces recommandations n'étaient pas de pure forme: la logique de l'inquisition ne la conduisait pas vers l'élucidation nécessaire à la cause des démoniaques. L'institution demeurait profondément théologienne et non juriste. Le fondement procédural de l'inquisition reposait moins sur la poursuite d'office et l'enquête que sur la troisième forme de poursuite (à côté de la procédure inquisitoire et de la procédure accusatoire) définie par Innocent III au canon 8 du concile de Latran : la dénonciation évangélique, issue de la correction fraternelle. Or la dénonciation orientait la poursuite vers la pénitence. La confession, rapidement obtenue par la menace, la terreur ou la torture conduisait à la demande d'absolution, chèrement négociée. Il importait à l'inquisiteur d'obtenir au plus vite cette confession, sans trop s'attarder dans l'enquête sur la fama ou sur la vérité, neutralisée par l'aveu. Paradoxalement, un accusé avait de meilleures chances avec les procédures sommaires chères au pape qu'avec l'inquisition, parce que la vérité pouvait contraindre le pape à la mansuétude, tandis que la mécanique de la culpabilité inévitable de tout pécheur entrânait tout inculpé dans la collectivité pénale de l'inquisition.

C'est peut-être ces problèmes de procédure qui ont provoqué ce que Jean-Patrice Boudet appelait plaisamment le « retard à l'allumage » dans la poursuite des sorciers au XIV siècle : tant que la papauté fut réticente à déléguer son pouvoir d'enquête, les limites matérielles de la justice pontificale empêchèrent la diffusion capillaire de l'imputation et de la répression. Et précisément, c'est l'abandon forcé de l'absolutisme 
pontifical, après les conciles de Constance et de Bâle qui ouvrit les premières campagnes judiciaires et doctrinales contre les sorciers et adorateurs du démon, dans les années 1430-1440. Mais le développement rapide de la démonologie avait été bien préparé par un pape qui tenait à considérer lucidement les zones obscures où le démon pouvait passer.

\section{NOTES}

1. B. Gui, Manuel de l'inquisiteur, éd. par G. Mollat, Paris, 1926-1927.

2. P. Paravy, De la chrétienté romaine à la Réforme en Dauphiné. Évêques, fidèles et déviants (vers 1340-vers 1530), Rome, 1993.

3. L'Imaginaire du sabbat. Édition critique des textes les plus anciens (1430 ca-1440 ca), réunis par M. Ostorero, A. Paravicini Bagliani, K. Utz Tremp en collaboration avec C. Chène, Lausanne, 1999.

4. R. KIECKHEFER, European Witch Trials. Their Foundations in Popular and Learned Culture, 1300-1500, Londres, 1976. Carlo Ginzburg commence sa série explicative des formes occidentales du sabbat en 1321, mais selon un modèle totalement opposé au nôtre. 5. Bonn, 1901.

6. L. THORNDIKE, A History of Magic and Experimental Science, vol. III, New York, 1934, p. 18 sq.

7. Voir N. Weill-Parot, Les «Images astrologiques » au Moyen Âge et à la Renaissance. Spéculations intellectuelles et pratiques magiques ( $\mathrm{XII}^{e}-\mathrm{XV}^{e}$ s.), Paris, 2002, p. 377-385 et Id., «Les intellectuels, l'Église et la magie dans la première moitié du xiv ${ }^{\mathrm{e}} \mathrm{s}$. " (mémoire de maîtrise, Paris I, 1990). Je tiens à remercier N. Weill-Parot pour ses commentaires sur le présent article.

8. "Quod cum morte fedus ineunt et pactum faciunt cum inferno. Demonibus namque immolant, hos adorant ».

9. Liber Sextus, V, II, cap. 8.

10. Cause XXVI, qu. 5, cap. 12, éd. Friedberg, col. 1080.

11. Voir A. Boureau, « De la félonie à la haute trahison. Un épisode : la trahison des clercs (version du xiie s.) », Le Genre Humain, 16-17, 1988, p. 267-291.

12. Venise, 1595, XLIII, 9, p. 341-342.

13. «Simpliciter et de plano ac sine strepitu et figura judicii... appellatione remota.» Lettre publiée par J.-M. Vidal, Bullaire de l'Inquisition française, Paris, 1913, $\mathrm{n}^{\circ} 284$, p. 403-404.

14. « Nonnulli etiam quandoque litterati in hoc se opponunt, pretendentes id ad tuum non expectare officium secundum canonicas sanctiones ».

15. J.-P. Boudet, «Les condamnations de la magie à Paris en 1398 », Revue Mabillon, n. s. 12 (t. 73), 2001, p. 121-157.

16. B. Hamilton, The Medieval Inquisition, Londres, 1981, p. 94.

17. Dans une lettre de 1336 adressée à l'official d'Avignon, Benoît XII, successeur de Jean XXII range à nouveau les sortilèges parmi les crimes qui touchent la foi (J.-M. Vidal, Bullaire, op. cit., $\mathrm{n}^{\circ}$ 153, p. 229-230). En 1405, Benoît XIII déclare nuls les privilèges 
des habitants du diocèse du Puy qui prétendaient que l'inquisiteur de Carcassonne ne pouvait les poursuivre pour maléfices (J.-M. Vidal, Bullaire, op. cit., $\mathrm{n}^{\circ} 332$, p. 473-474). 18. La première édition a été procurée par Jean Chappuis en 1500. Pour la formation des deux collections, voir A. M. Stickler, Historia Iuris Canonici. Institutiones Academicae. T. I : Historia Fontium, Rome, 1950, p. 270-271.

19. Les seules mentions de la bulle se trouvent, on l'a dit dans le manuel de Nicolas Eymerich (1376), dans les Annales ecclésiastiques de Rinaldi et dans un bullaire romain du xviiie ${ }^{\mathrm{s}}$.

20. Voir A. MAIER dans « Eine Verfügung Johannis XXII über die Zuständigkeit der Inquisition für Zauberprozesse », Archivium Fratrum Praedicatorum 32, 1952, p. 226-246.

21. A. Maier, loc. cit., p. 231.

22. Publiée par R. Manselli, « Enrico del Carretto e la consultazione sulla magia di Giovanni XXII », dans Miscellanea in onore di Monsignore Martino Giusti, t. II, Vatican, 1978, p. 97-129.

23. Il est possible aussi que l'interrogation doctrinale ait été anticipée par Guido Terreni, un des dix experts de la consultation de 1320, dans son sixième quolibet « Estce que celui qui baptise une chose sans âme ou sans raison et non pas un homme est hérétique?", ms. BAV Borghese $39, \mathrm{f}^{\circ} 238 \mathrm{v}^{\circ}-240 \mathrm{v}^{\circ}$, que je publie en annexe de la consultation. Mais la date de ce quolibet demeure incertaine.

24. « Fecisti plantas pedum eiusdem mulieris iuxta carbones accensos apponi... ", texte publié par J.-M. Vidal, Bullaire, op. cit., p. 51-52.

25. « Diu post confessionem debitum nature persoluit...verum quia dubitatur ne propter predicta tormenta citius decesserit quam alias decessisset mulier supradicta si tormentata minime extitisset. »

26. «Erronea et horrenda contra catholicam fidem fuit confessa et multos consocios et complices reuelauit...que omnia sic inuenta, ut communiter creditur, numquam reuelata fuissent nisi mediantibus tormentis eiusdem predicta mulier reuelasset. ». 27. « De consilio proborum qui se asserebant uidisse penis examinati hereticos in partibus Tholosanis ».

28. J.-M. Vidal, Bullaire, op. cit., $\mathrm{n}^{\circ}$ 24, p. 53-54.

29. Ex certa sciencia : sur cette clausule de l'absolutisme pontifical, voir A. Boureau, La Loi du royaume. Les moines, le droit et la construction de la nation anglaise, Paris, 2001, avec renvoi aux travaux de Jacques Krynen.

30. Publiée par J.-M. Vidal, Bullaire, op. cit., p. 61. Une meilleure édition a été procurée par A. Maier, loc. cit., p. 226-227.

31. J.-M. Vidal, Bullaire, op. cit., $\mathrm{n}^{\circ} 72$, p. 118-119.

32. La commission fut réitérée le 8 novembre 1327, ibid., nº 78 bis, p. 129-130.

33. Voir A. Boureau, « Saints et démons dans les procès de canonisation du début du xiv ${ }^{\mathrm{e}}$ s. ", à paraître dans les actes du colloque de Budapest sur les procès de canonisation, dir. Gábor Klaniczay.

34. B. Gui, Manuel de l'inquisiteur, éd. et trad. par G. Mollat, op. cit., t. I, p. 52.

35. Publiées par J.-M. Vidal, Bullaire, op. cit., nº 103, p. 154-156.

36. Henri de Chamayou.

37. Pierre Brun.

38. La qualification d'hérésie, de la part du pape, à propos des invocations démoniaques n'a jamais cessé. Voir, par exemple, une lettre de 1323, qui désigne des commissaires pour juger le moine Guillaume de Figeac, accusé de « dévier de la foi catholique » en pratiquant l'alchimie et la nécromancie (J.-M. Vidal, Bullaire, op. cit., $n^{\circ}$ 50, p. 87-88). 
39. F. Graf, La Magie dans l'Antiquité gréco-romaine. Idéologie et pratique, Paris, 1994. 40. Voir le récit par Pierre le Vénérable, vers 1137, d'un usage magique de l'hostie consacrée par un paysan désireux de retenir ses abeilles : Livre des merveilles de Dieu (De miraculis), introduction, traduction et notes de J.-P. Torrell et D. Bouthillier, Fribourg/ Paris, 1992, p. 70-72. Je remercie Charles de Miramon de m'avoir signalé ce texte. 41. Voir les travaux réalisés autour de Richard Kieckhefer et Claire Faenger aux ÉtatsUnis, autour de Jean-Patrice Boudet et Henri Bresc en France, notamment.

42. Dans sa biographie collective des deux premières générations de dominicains, écrite au début des années 1260, Gérard de Frachet ne rapporte qu'un seul cas de frère qui se voue à l'alchimie, et il ne trouve à lui reprocher que son désir de s'enrichir rapidement. Son activité consiste alors essentiellement à se rendre en Sardaigne pour y collecter des minéraux rares. Son funeste sort ultime ne s'explique que par cet abandon de Dieu au profit de la richesse séculière (Vitae Fratrum Ordinis Praedicatorum, éd. par B.-M.

Reichert, Rome-Stuttgart, Monumenta Ordinis Fratrum Praedicatorum Historica, 1897, p. 290).

43. La Condamnation parisienne de 1277, éd. et trad. par D. Piché avec la collaboration de C. Lafleur, Paris, 1999, p. 77.

44. A. Paravicini Bagliani, Il corpo del papa, Turin, 1994.

45. Préface à Le crisi dell'alchimia, Micrologus 3, 1995, p. VIII.

46. Voir l'édition du procès dans J. Shatzmiller, Justice et injustice au début du XIV $s$. L'enquête sur l'archevêque d'Aix et sa renonciation en 1318, Rome, 1999.

47. Voir une lettre de février 1330, dans Lettres secrètes et curiales du pape Jean XXII (1316-1334) relatives à la France, éd. par A. Coulon et S. Clémencet, fasc. 8, Paris, 1965 $\mathrm{n}^{\circ}$ 4100, p. 104-105 [abrégé désormais Coulon-Clémencet] : lettre à Jean de Badas, inquisiteur franciscain de Marseille sur un crime nefandum commis par Gantalmus Gantalmi, notaire, et sa femme Berengère, instigatione diabolica circumventi à l'encontre de Guillaume de Baucio, sire de Berre.

48. Texte publié par J. HANSEN, Quellen und Untersuchungen, op. cit., $\mathrm{n}^{\circ} 3, \mathrm{p} .2$.

49. Notons qu'en 1318 , les rites de consécration des miroirs et images paraissent spécifiques, alors qu'en 1320 , dans les questions posées par le pape aux experts, les invocateurs de démons utilisent le rite catholique du baptême pour préparer leurs images.

50. A. Paravicini Bagliani, Il corpo del papa, op. cit.

51. C. H. Josten, «The Text of John Dastin's letter to Pope John XXII », Ambix, 4, 1951, p. 46-51.

52. E. Albe, Autour de Jean XXII : Hugues Géraud, évêque de Cahors : l'affaire des poisons et envoûtements en 1317, Cahors, 1904, p. 163-164.

53. Processus Bernardi Deliciosi : The Trial of Fr. Bernard Délicieux, 3 September-8 December 1319, édité par A. Friedlander, Philadelphie, 1996, p. 62. Pour une étude complète du dossier, voir A. Friedlander, The Hammer of the Inquisitors. Brother Bernard Délicieux and the Struggle against the Inquisition in Fourteenth-Century France, Leyde, 2000.

54. Coulon-Clémencet $n^{\circ} 2969$, p. 151.

55. Coulon-Clémencet $n^{0} 2395$, p. 47.

56. Sermon sur la vigile de l'Épiphanie, 5 janvier 1332, éd. par M. Dykmans, Les Sermons de Jean XXII sur la vision béatifique, Rome (Miscellanea Historiae Pontificiae 34), p. 145. 57. Les actes du procès ont été publiés par J.-M.Vidal, « Procès d'inquisition contre Adhémar de Mosset », Revue d'Histoire de l'Église de France, 1, 1910. L'anecdote se trouve à la p. 713. 
58. Ces interrogations sur la « situation » spirituelle étaient fréquemment exprimées. Dans sa correspondance avec les grands de ce monde, le pape doit souvent répondre à ce genre de question, en termes à vrai dire assez généraux.

59. Coulon-Clémencet, fasc. 8, Paris, $1965, n^{\circ} 4197$, p. 126. Lettre analogue en février 1331 ( $\mathrm{n}^{\circ} 4452$, t. 9, p. 41).

60. On peut se demander si ce n'est pas cette fidélité littérale au texte biblique qui a contribué à pousser le pape à intervenir sur la question de la vision béatifique, question où les partisans de la vision directe de Dieu avant le jugement final ne trouvaient aucun appui scripturaire direct.

61. On trouve une formulation parallèle dans Quia quorumdam mentes (10 novembre 1324).

62. Voir A. Boureau, « Droit naturel et abstraction judiciaire. Hypothèses sur la nature du droit médiéval », Annales HSS, 57, 6, 2002, p. 1463-1488.

63. Voir A. Boureau, «La redécouverte de l'autonomie du corps : l'émergence du somnambule (xiiie-xive s.) », Micrologus, I, 1993, p. 27-42.

64. Sur toutes ces questions, je me permets de renvoyer au chap. 8 de mon ouvrage Théologie, science et censure au XIII ${ }^{e}$ s. Le cas de Jean Peckham, Paris, 1999.

65. Publié par J. Rius Serra, dans Sancti Raymundi de Penyafort opera omnia, t. III, Diplomatario (Documentos, Vida antigua, Cronicas, Processos antiguos), Barcelone, 1954, p. 74-82.

66. Cette typologie fut reprise par le pape Alexandre IV une dizaine d'années plus tard et éditée par Boniface VIII dans le Sexte (L. 5, tit. 2, cap. 2, 6, 11, éd. Friedberg, II, col. $1069,1071,1073)$. Voir aussi le traité Doctrina de modo procedendi erga hereticos (vers 1280), dans Martène et Durand, Thesaurus novus anecdotum, t. 5, Paris, 1717, col. 1797 et la Practica de Bernard Gui (p. 226-232).

67. Bien avant la création de l'Inquisition, le troisième concile de Latran (1179) avait frappé d'anathème et privé de sépulture les defensores et receptatores d'hérétiques (Décrétales, L. 5, tit. 7, cap. 8, éd. Friedberg, II, col. 1780).

68. Ibid., p. 29-32.

69. Texte édité par J. Coste, Boniface VIII en procès. Articles d'accusation et dépositions de témoins (1303-1311). Édition critique, introduction et notes, Rome, 1995, p. 153.

70. Nogaret, originaire de Saint-Félix-de-Caraman, haut-lieu cathare, petit-fils d'un ministre hérétique, avait certainement une bonne connaissance de la persécution de l'hérésie, en dépit de sa formation de civiliste.

71. Directorium, op. cit., seconde partie, question 2.

72. Processus, op. cit., p. 180.

73. E. PETERS, Inquisition, Berkeley, 1988.

74. R. KIECKHEFER, « The Office of Inquisition and Medieval heresy : the Transition from a Personal to an Institutional Juridiction », Journal of Ecclesiastical History, 46, 1995, p. 36-61.

75. Ainsi, le pape décida de suspendre le droit d'asile dans les églises au détriment des hérétiques mais pas spécifiquement des auteurs de sortilèges (Lettre au roi de France Philippe VI, en 1328, publiée par J.-M. Vidal, Bullaire, op. cit., nº 79, p. 130-131).

76. Éd. FRIEDBERG, t. II, col. 1078.

77. Ibid. col. 1200.

78. Voir la lettre dure que lui adressa le pape Jean XXII le 6 octobre 1332 (J.-M. Vidal, Bullaire, op. cit., $\mathrm{n}^{\circ} 124$, p. 184).

79. Coulon-Clémencet, $\mathrm{n}^{\circ} 4539$, fasc. 9, p. 59-60. 
80. L'attention prêtée à Philippe le Bel et à Jean XXII ne doit pas faire oublier que ce type d'accusation politico-démonologique est d'époque, comme le montre, dans un tout autre contexte, le procès intenté à Walter Langton, évêque de Coventry en 1301-1303, avec mention d'adoration diabolique (voir A. Beardwood, « The Trial of Walter Langton, bishop of Lichfield, 1307-1312 ", Transactions of the American Philosophical Society, N.S., 54, p. III, Philadelphie, 1964.

81. Voir J. Coste, Boniface VIII en procès, op. cit.

82. A. Rigault, Le Procès de Guichard évêque de Troyes, 1308-1313, Paris, 1896.

83. J. Favier, Un conseiller de Philippe le Bel : Enguerrand de Marigny, Paris, 1963. Il faut mentionner, peu après, le procès contre le cardinal Francesco Gaetani, poursuivi par les cours royales pour attentat contre le roi, son frère et deux cardinaux, à l'aide d'images magiques (voir C. Langlois, «L'affaire du cardinal Francesco Gaetani (avril 1316) », Revue historique, 63, 1897, p 56-71).

84. E. Albe, Autour de Jean XXII, op. cit.

85. R. Michel, « Le procès de Mateo et Galeazzo Visconti : l'accusation de sorcellerie et d'hérésie, Dante et l'affaire de l'envoûtement (1320) ", Mélanges d'archéologie et d'histoire, 29, 1909, p. 269-327.

86. F. Bock, «I processi di Giovanni XXII contro i Ghibellini delle Marche », Bolletino dell'Istituto storico italiano per il Medio Evo, 57, 1941, p. 19-43.

87. Voir J.-M. Vidal, « Le sieur de Parthenay et l'Inquisition (1323-1325) », Bulletin historique et philologique, 1903, p. 414-434.

88. J.-M. Vidal, Bullaire, op. cit., $\mathrm{n}^{\circ}$ 20, p. 44 et $\mathrm{n}^{\circ}$ 76, p. 126-127.

89. J.-M. Vidal, Bullaire, op. cit., $\mathrm{n}^{\text {os }} 109$ et 110 , p. 167-171.

90. J.-M. Vidal, Bullaire, op. cit., $\mathrm{n}^{\circ}$ 90, p. 144.

\section{RÉSUMÉS}

L'institution de la démonologie, prise comme discipline autonome vouée à la détection et à la poursuite des démons et des sorciers, est généralement située au début de la grande chasse à la sorcellerie, au XVe siècle. Le présent article suggère d'avancer cette chronologie d'un bon siècle, en considérant les efforts soutenus du pape Jean xxII, à partir des années 1320, en vue de qualifier comme hérésie l'invocation des démons. La mise en œuvre de commissions d'enquêtes doctrinales ou judiciaires manifeste cette orientation, explicable par les inquiétudes du pape devant le développement des pratiques de la magie et de l'astrologie et par la conviction que les actes dévoilaient des opinions soigneusement dissimulées par le secret des consciences. Seule la méfiance persistante de Jean xxII, puis de ses successeurs vis-à-vis des tribunaux d'inquisition retarda le lancement des poursuites contre les sorciers.

Satan the Heretic: the Judicial Institution of Demonology under John XXII. The institution of demonology, understood as an autonomous discipline dedicated to the detection and pursuit of demons and sorcerers, is generally located in the 15th century, at the beginning of the great witch-hunts. This article suggests that we advance this chronology by at least a century, and consider the sustained efforts of Pope John XXII, who, throughout the 1320s, strove to define the invocation of demons as a heretical act. The establishment of commissions of doctrinal or judicial 
inquiry testify to the Pope's orientation, which can be explained by his anxiety in the face of developing practices of magic and astrology, and by his conviction that such acts revealed opinions that had been carefully concealed in the depths of individual conscience. The launching of a full-scale persecution of witches was delayed only by the persistent suspicions of John XXII and his successors regarding the inquisitorial courts.

\section{INDEX}

Keywords : inquisition, heresy, intention, demonology, John XXII, magic, judicial procedure Mots-clés : hérésie, démonologie, Jean XXII, magie, procédure

\section{AUTEUR}

ALAIN BOUREAU

EHESS, CRH, GAS, 54, boulevard Raspail, F-75006 Paris 